\title{
The Impact of Work Stress on Employee Performance: Based in Banking Sector of Faisalabad, Pakistan
}

\author{
Muhammad Ehsan \\ Department of Management Sciences, National University of Modern Languages Islamabad \\ H-9 Sector, Islamabad, Pakistan
}

\begin{abstract}
The study investigated the impact of work stress on employee productivity. The study sought to find out how work-related stress could affect the productivity of banking staff of Faisalabad, Pakistan. In addition, it identified certain factors which contribute to work stress among banking. The target populations comprised all employees from the five to six bank of Faisalabad city (Bank AL Habib, Faysal limited bank, MCB, Meezan Bank, J.S Bank, Bank Al-Falah). The stratified random sampling technique was used to select 50 participants for the study. Questionnaire was the instrument used to elicit information from the respondents. Descriptive statistic of table and percentage were used to answer the research questions raised to guide the study while regression and correlation method was adopted to analyze the research hypotheses generated for the study. To check the impact of work stress, the stress related variables are impact of workload, impact of role ambiguity, impact of role conflict. The findings of this study revealed that there is significant relationship between work stress and employee's productivity in banking sector.
\end{abstract}

Keywords: Work stress and Employee's productivity

DOI: $10.7176 / \mathrm{EJBM} / 11-1-04$

\section{INTRODUCTION}

Stress can be defined as pressure work stress can be elaborated as resistance to come to work and a feeling of continuous pressure. Hence work stress is physical and emotional action that takes place when there is gap between job requirements, capabilities and resources. Employees performance is an essential element of organization success. Employees performance can be significantly delayed by high levels of stress experienced in the work environment. Stress is a universal element and individual in every walk of life have face it. The employees working in different organizations must deal with stress. Especially Bankers are under great stress due to many antecedents of stress. The stress contributes to decreased organization performance, decreased employee's overall performance, high staff turnover and absence due to health problems. (Islam et al, 2012) Stress can be defined in general term as people feel pressures in their own life. The stress due to work load can be defined as reluctance to come to work and a feeling of constant pressure associated with general physiological, psychological and behavioral stress symptoms. Hence stress is the harmful physical and emotional responses that occurs when the requirements of the job do not match the capabilities, resources, or needs the worker and he/she expressed that job stress can lead to poor health and even injury.

(Robbins, 2001) defines stress as a dynamic condition in which the individual is confronted with an opportunity, constraint, or demand related to what he or she desires and for which the outcome is perceived to be both uncertain and important. Stress results from a mismatch between the demands and pressures on the person, on the one hand, and their knowledge and abilities, on the other. It challenges their ability to cope with work. This includes not only situations where the pressures of work exceed the workers ability to cope but also where the worker's knowledge and abilities are not sufficiently utilized and that is a problem for them. Stress is one of the burning issues that banking sector must deal so that employees can comfortably produce quality work. Stress causes an imbalance in one's life because it leads to depression and thus damages health, attitude and work behavior.

(Sharpley et al, 1996) stated that there is also evidence that banking is experiencing role ambiguity. Reported that lack of regular feedback about how well bankers were doing was the highest source of stress. The lack of regular feedback received by banking was reported earlier (Dua, 1994) Feedback is important to enable the bankers to evaluate their performance on the job and how they are progressing in their effort toward task accomplishment. Since positive feedback may serve as reinforcement to the self-efficacy belief that leads to higher performance and less stress, bankers who do not receive regular feedback may experience considerable uncertainty about their role performance. 


\section{METHODOLOGY \\ 2.1 Introduction}

This chapter present the methodology used to carry out the study. It discusses the conceptual model of the study, Research hypothesis, Type of the research, Participants, Sample, Sampling techniques, Data collection sources.

\subsection{Type of the Research}

Type of research is descriptive. Descriptive research is a design to depict the participants in an accurate way. This design was considered appropriate because it allows to collect relevant data on the research variables and analyses them using the appropriate techniques. It also allows to examine the existing relationship between the dependent variable (Employees performance) and the independent variable (Work stress).

\subsection{Participants}

The target population is the banks of Faisalabad. The six banks were selected for this study. These Banks were selected to check the impact of stress on employee performance. Bank AL Habib, Faysal limited bank, MCB, Meezan Bank, J.S Bank, Bank Al-Falah

\subsection{Sample Size}

The sample population is a subset of the entire population, and inferential statistics is to generalize from the sample to the population. A sample size of 50 respondents was used for the study.

\subsection{Sampling Technique}

It is noted that, analyses are best when conducted on samples that are still fresh. Therefore, sampling was used to select a portion of the population to represent the entire papulation. He emphasizes the need for a researcher to select a sample from which he wishes to seek information, using appropriate sampling Techniques. conveniences sampling a type of Non-probability was used to select sample and gather data.

\subsection{Data Collection Sources}

Both primary and secondary data used in this research. The source of secondary data was internet, articles, and books and the source of primary data was questionnaire.

Closed-ended questionnaires were designed for the respondents. The questionnaires were divided into various sections to capture the critical areas spelt out in the objectives for the study.

\subsection{Data Collection}

Copies of the questionnaire were personally handed to respondents at their offices. After some minutes, I went back and collected the answered questionnaires because the respondents may forget to fill in the questionnaire or misplace them entirely. The questions were thoroughly explained to the respondents after copies of the questionnaire were handed to them. The purpose was to help the respondents understand the relevance of the research and provide their independent views on the questionnaire items given them. To have a valid and a reliable data, I ensured that the questionnaires were well prepared which allowed error minimization.

The questionnaire had close-ended questions which respondents were asked to tick the appropriate answer.

\subsection{Background of the Study}

(Baker, 2004) it was reported that bankers had higher levels of stress at work, almost double the rate (40\%) when compared with other professions. A recent survey carried out by the Association of bankers found that $69 \%$ of banking and related staff found their job stressful and 50\% reported psychological distress.

(Christo and Pienaar ,2006) for example, argued that the causes of occupational stress include perceived loss of job, and security, sitting for long periods of time or heavy lifting, lack of safety, complexity of repetitiveness and lack of autonomy in the job.

(Taylor Shelley, 1995) describes stress as a negative emotional experience accompanied by predictable biochemical, physiological, cognitive and behavioral changes that are directed either toward altering the events or accommodating its effects.

\subsection{Scope of the Study}

The study focused on banking sector of Faisalabad as one of the major banking sector of Pakistan to get in depth and comprehensive understanding of what is happening at banking sector of Faisalabad and make the research meaningful. Drawbacks are an inevitable part of almost every venture individual carry out and overcoming them prepare or fortifies one for other task ahead. Even though these challenges to some extent hampered the progress of the study, they also helped in putting researcher on their toes to work tirelessly around the clock in making the success of this study a reality. 
In as much as loss of commitment and zeal was employed in conducting an intensive and through study, certain impediments were encountered.

\subsection{The Objectives of this Study}

- Find out whether stress has any effect on the performance of employees in banking sector of Faisalabad, Pakistan.

- Ascertain the causes of stress in banking sector.

\subsection{Research Question}

- Does stress have any effect in the proactivity of employees in banking sector?

- What are the causes of stress in banking sector.

\subsection{Hypothesis}

- H1: There is no impact of work stress on employee's performance

\subsection{Statement of Problem}

Most organization with the aim of attaining higher performance end up saddling employees overload of work to meet deadline and this might have psychological and physical effects on the employees which may result somethings contrary to what these organization want to achieve. Although organization are paying more attention than in the past to the consequences of the trauma their employees go through when they place extraordinary demands on them, there is still more room for improvement. Again, to generate enough revenue to be self-sustaining and to be able fund the acquisition of modern equipment meant efficient services provision and optimal employees of resources. There has been the need for a continuous change in management strategies, administration and the demand of employees to perform have been increasing.

\subsection{Research Structure}

The entire study is divided into five (5') chapters. Chapter one gives a general introduction about the study, while chapter two focuses on some theoretical frameworks and reviews of related literature about the subject. The chapter three presents the methodology used in the data collection. Chapter four analyses, summarizes and presents the data for the study. The final chapter provides a summary of findings, conclusion and makes recommendation for the solution of the problem of stress.

\subsection{Significance of the Study}

The results have revealed the main sources and level of stress being experienced by most of baking staff in Faisalabad, Pakistan. The recognition of these facts would enable the appropriate authorities to take the necessary intervention steps to reduce the job stressors and level of stress and the negative consequences associated with them, particularly among those who said they were under much and extreme stress. This would help banking administrators to adopt appropriate coping mechanisms and control stressors so that they would find and operate at a level that is most comfortable to them and this will enable them to be more productive, effective and efficient in the performance of their duties. Work stress is not being given the attention it deserves and so very little has been done as far as assessing the role of stress on job performance within banking sector. It is in the light of this that this study is deemed important, as it will:

Create awareness among banking administrators on the need to provide the needed platform to help staff deal with their stresses. The study has the potential to stimulate interest in the study of stress among workers in Pakistan.

\subsection{Research Ethics}

Research that involves human subjects or participants raises unique and complex ethical, legal, social and political issues. Research ethics is specifically interested in the analysis of ethical issues that are raised when people are involved as participants in research. During my data collection. I have followed three main objectives of research ethics. The first and broadest objective is to protect human participants. The second objective is to ensure that research is conducted in a way that serves interests of individuals, groups and/or society. Finally, the third objective is to examine specific research activities and projects for their ethical soundness, looking at issues such as the management of risk, protection of confidentiality and the process of informed consent.

\section{LITERATURE REVIEW}

3.1 Job Stress

(Malek, 2010; Medi bank Private Inc., 2008) stated that job stress is an unpleasant emotional situation that an individual experience when the requirements of job are not counter balanced with his ability to cope the 
situation. It is a well-known phenomenon that expresses itself different in different work situations and affects the workers differently.

Jamshed et al., (2011) suggested. An individual in his or her job in bank face stress "The workplace is potentially an important source of stress for bankers because of the amount of time they spent in their respective banks." And that stress often decreases their performance. "Therefore, occupation of individuals could be a major source of stress in the given circumstances. When individuals face stress due to various conditions of their occupation and fail to cope with stress, it results into burnout," (IBDM). Basically, in banking sector lack of administrative support from boss(manager), work overload \& time pressure, risky ness of job, poor relationship with customers \& coworkers, and work family balance cause stress which in turns decrease employee performance.

Materson (1980) was contributed the same "Causes of stress are many like work load, cuts in staff, change at work, long work hours, shift work, lack of supervision, inadequate training, inappropriate working conditions, too heavy responsibilities and poor relations with colleagues." The same was identified by Ganster \& Loghan, (2005) "huge and multi fields literature points a lot of key factors such as work environment, management support, workload etc. in determining how stressful the work can be and its effect on employee physical and mental health.

(Bowing Harvey, 2001) According to them stress occurs with the interaction between an individual and the environment, which produces emotional strain affecting a person's physical and mental condition. Stress is caused by stressors, which are events that create a state of disequilibrium within an individual. These authors also stated that the cost of too much stress on individuals, organizations, and society is high. Many employees may suffer from anxiety disorders or stress-related illnesses. In terms of days lost on the job, it is estimated that each affected employee loses about 16 working days a year because of stress, anxiety or depression.

(Ritchie and Martin, 1999) states that stress was described in terms of external, usually physical, forces acting on an individual. Later it was suggested that the individual's perception of, and response to, stimuli or events was a very important factor in determining how that individual might react, and whether an event will be considered stressful. These authors further contended that most researchers acknowledged that both external and internal factors affect stress. They viewed stress as a response to external or internal processes, which reach levels that strain physical and psychological capacities beyond their limit.

\subsection{Types of Stress}

(Taylor ,1995) stated that there are four major types of stress, which she explains as follows:

3.2.1 Acute stress: This type of stress is the most common and most recognizable form of stress. This is the kind of stress which the individual knows exactly why he is stressed. Normally, the body rests when these stressful events cease and life gets back to normal because the effects are short-term. Acute stress usually does not cause severe or permanent damage to the body.

3.2.2 Traumatic stress: It is a severe stress reaction that results from a catastrophic event or intense experience such a natural disaster, sexual assault, life-threatening accidents, or participation in a combat. Here, after the initial shock and emotional fallout, many trauma victims gradually begin to recover. But for some people, the psychological and physical symptoms triggered by the trauma do not go away. The body does not return to equilibrium, and life does not return to normal.

This condition is known as post trauma stress disorder. Common symptoms of this type of stress are flashbacks or nightmares about the trauma, avoidance of places and things associated with the trauma, hyper vigilance for signs of danger and irritability and tension.

3.2.3 Chronic stress: She describes this type of stress as unrelenting demands and pressures seemingly interminable periods of time. This stress wears the individual down day after day and year after year with no visible escape. It grinds away both emotional and health of the individual leading to breakdown and even death.

3.2.4 Episodic acute stress: This episodic acute stress is a situation where the individual's life experiencing this type of stress are very chaotic, out of controlled and they always seem to be facing multiple stressful situation. They are always in a rush, always late, always taking on too many projects, handling too many demands. Those who are prone to this type of stress include "TYPE A" personality. If an individual is prone to episodic acute stress, he may not know it or admit it. He may be wedded to a life style that promotes stress. Unfortunately, people with episodic acute stress may find it so habitual that they resist changing their lifestyle until they experience severe physical symptom

\subsection{Sources of Stress}

(Matthews G, 2001) defined stress can be experienced from four basic sources.

3.3.1 The Environment - the environment can bombard you with intense and competing demands to adjust. Examples of environmental stressors include weather, noise, crowding, pollution, traffic, unsafe environment, and substandard housing, and crime. 
Social Stressors- we can experience multiple stressors arising from the demands of the different social role we occupy, such as parent, spouse, caregiver, and employee. Some examples of social stressors include deadlines, financial problems, job interviews, presentations, disagreements, presentations, disagreements demand for your time and attention loss of a loved one, divorce and co-parenting.

3.3.2 Physiological- situation and circumstances affecting our body can be experienced as physiological stressors. Examples of physiological stressors include rapid growth of adolescence, menopause, illness, aging, giving birth, accidents, lack of exercise, poor nutrition, and sleep disturbances.

3.3.3 Thoughts- your brain interprets and perceives situations as stressful, difficult, painful, or pleasant. Some situations in life are stress provoking, but it is our thought that determines whether they are a problem.

\subsection{Factors that Contribute to Work Stress}

3.4.1 Work Overload: (Rehman et al., 2010) High level of stressors like heavy work load and uncertainty about supervisor's expectations are associated with physical symptoms. Stress also gets caused when employee does not fulfill the demand of job and supervisor (Schnall, 2011) Excessive work load and conflicting expectations are the good examples of working conditions. 40 percent workers reported that their job is extremely stressful. In U.S., 80 percent of American workers feel stress on job.

(Bacharach et al., 1991) Previous studies have shown different factors associated to occupational stress. For example, work overload that refers to when the employees' role expectations exceed the resources or time available to fulfill assigned responsibilities.

(Manzoor, 2011) There are several factors which cause stress in employees at job and these factors are job timings, pay, bonus, work load and peer attitude. (Badar, 2011) Work load, technological problems, higher targets, compensation and salary, outcomes of decisions, management and peer support behavior, longer time frame are the main factors of causing stress in employees. (Dar et al., 2011) With increase in designation, stress increases and factors of creating stress in employees are feeling undervalued, work home interface, fear of joblessness, traumatic incidents at work and economic instability.

(Khattak et al., 2011).stated that in Pakistan, employees experienced stress because of workload, technological problems at work, long working hours, inadequate salary, insufficient time for family and job worries at home Stress is a cause of dissatisfaction among the employees like role conflicts, work intensification, relationship with (Ismail \& Hong, 2011) Colleagues and unfavorable working conditions are the major factors of creating stress In health sector, where female faces a stressful situation due to irregular and long working hours, role pressure and Work overload, they may become nervous and anxious.

(Tsaur and Tang, 2012). Inflexible work hours, work over load, risky job and poor coworker relations are the main contributor to job stress, which create dissatisfaction among the employees (Shahid, 2012).

3.4.2 Role Conflict: (Rosen et al., 2010) stated that role conflict refers to incompatible requirements and expectations that the employees receive from their supervisor or coworker. (Nwadiani, whom an individual must interact hold conflicting expectations about that individual's behavior.

(Luthans, 2002) differentiates three major types of role conflict. One type is the conflict between the person and the role. For example, a production worker and a member of a union are appointed to head up a new production team. This new team leader may not really believe in keeping close control over the workers and it would go against this individual's personality to be hardnosed but that is what the head of production would expect. A second type of intra role conflict creates contradictory expectations about how a given role should be played. Finally, inter role conflict results from differing requirements of two or more roles that must be played at the same time. For example, work roles and non-work roles are often in such conflict.

(Zhao et al., 2010) The role arises when more demands have been taken place upon the individual by the peers, supervisors, subordinates. Such type of stress is more dominant in the jobs which have lack of descriptions or unclear descriptions and these require the conceptual thinking and decision making.

3.4.3 Role Ambiguity: (Karasek Jr, 1979; Beehr and Bhagat, 1985) stated that Role ambiguity is another factor that leads to job stress, thus it occurs when the expectations, objectives, responsibilities have not been clearly designed for employees. (Malik, 2011) stated that the employees become ambivalent to predict their supervisor's reactions to their tasks as" success" or as" failure. Finally, long hours, work overload, time pressure, difficult or complex tasks, lack of breaks, lack of variety and poor work conditions (for example, space, temperature, light) are causes of occupational stress.

3.4.4 Performance: (Meneze, 2006) defined performance as the employee's ability to produce work or goods and services according to the expected standards set by the employers, or beyond the expected standards.

(Mathis and Jackson, 2000) defined performance as a measure of the quantity and quality of work done considering the cost of the resource it took to do the work. Steers (1991) believes it is useful from a managerial standpoint to consider several forms of counterproductive behavior that are known to result from prolonged stress.

(Thompson and M.C. Hugh,1995) believe when specifically, regarding stress in the workplace, 
contemporary accounts of the stress 'process' often follow the notion of stress xxxix as resulting from a misfit between an individual and their environment, where internal or external factors push the individual adaptive capacities beyond his or her limit. However, no two people react to the same job in the very same way, because personal factors also influence stress. For example, type personalities; people who are workaholics and who feel driven to be always on time and meet deadlines, normally place themselves under greater stress than do others.

\subsection{Effects of Job Stress on Employees' Performance}

(Khattak et al, 2011). Stress puts drastic effects on employees. Employees in stress cannot meet the expectations of their organization, because of facing physical, psychological and organizational burnouts. (Ismail \& Hong, 2011) Employees in service organization are subjected to high degree of work related stress, which is the major reason for employees' poor performance at job. Job stress affects negatively on the female employee's wellbeing which creates dissatisfaction and negative emotions towards work and ultimately their performance decreases.

(Tsaur\&Tang, 2012) Most of the employees in organizations feel that their job is stressful, that in return decreases their performance.

(Barbara et al., 2009) The condition of "high demand and low control" is highly associated with cardiovascular and heart problems, anxiety, demoralization and depression, use of drug (Alcohol) and susceptibility to a wide range of infectious diseases. The condition of "high effort and low control" is also associated with high rate of cardiovascular, anxiety, depression and conflict related problems. Where both these conditions are present, high incidents of back pain and receptive strain injuries are occurred. Collectively both these conditions stifle the performance of employees.

(Malik, 2011) stated that employees having no control over their work, lack of financial rewards, unsupportive management system face serious physical problems, such as heart disease; increase in blood pressure and headaches. (Pediwal, 2011) At job, stress affects the physical, Psychological and financial balance of the employees. In result of stress, employees are absenting from organization and loose working hours. (Shehzad et al., 2011) Stress increases the employee turnover from job, which influences the employees as well as organizational performance.

(Salami et al., 2010) Stress directly affects the employees' performance and both are mutually related to each other, without stress there is a death of human being. (Coetzee and Devilliers, 2010) Role ambiguity, work relationships, job security, lack of job autonomy, work home interface, compensation and benefits, lack of management support are the key sources of creating job stress. Due to these sources of stress, employee engagement to work decreases. (Nowack, 2010) It negatively affects the performance of employees. It is estimated that 40 to 60 percent of all employees rate their jobs as being stress and having drastic impact on their family balance and health. More than 70 percent of U.S workers think that there is no healthy link between their family lives and work, and more than 50 percent women in U.S have chosen to stop out from professional careers after large investment in formal education and training.

(Bytyqi et al., 2010) Stress has a considerable importance for the organizational concern, because it has a direct effect on the employee's health and their performance. (Jing, 2008) Stress influences the people both in positive and negative way. At initial stage, it influences positively by motivating employees, but if it is consistent for long time it influences the people in negative way through increasing frustration, anxiety and tardiness. (Ongori and Agolla, 2008) In the organization, if stress is not ignored then it destroys the profitability of the organization gradually. (Lambert et al., 2007) At job female employees are affected more than the male employees through stress. With increase in age, job stress also increases. (Shah, 2003) Hyper stress is found to be responsible for physical and psycho-physiological disorders, which leads to poor performance of an employ.

(Chase and Aquilano in Mark 2012) stated that Work-related stresses may be responsible for organizational outcomes such as decline in performance, dissatisfaction, lack of motivation and commitment, and an increase in absenteeism and turnover.

(Chase and Aquilano in Mark 2012) stated that performance is measured in terms of outputs per labor hour. However, this measurement does not ensure that the firm will make money (for example when extra output is not sold, but accumulated as inventory). To test whether performance has increased, the following questions should be asked 'has the action taken increased output or has it decreased inventory?' "Has the action taken decreased operational expense?" This would then lead to a new definition which is: performance is all the actions that bring a company closer to its goals.

(Mathis and Jackson, 2000) defined performance as a measure of the quantity and quality of work done considering the cost of the resource it took to do the work. Steers (1991) opined that from a managerial stand point it is useful to consider several forms of counterproductive behavior that are known to result from prolonged occupational stress. Thompson and MC Hugh (1995) believe when specifically, regarding stress in the workplace, contemporary accounts of the stress "process" often follow the notion of stress as resulting from a misfit between an individual and their environment, where internal or external factors push the individual 
adaptive capacities beyond his or her limit.

\section{DATA PROCESSING AND ANALYSIS}

This chapter describes the results of data analysis. The Statistical Package for Social Sciences was used to explore the data. The first part of this chapter touches on the profile of the respondents. Later reliability analysis and descriptive analysis are used to assess the goodness of the measures.

\subsection{Frequency Analysis (Profile of respondents)}

Frequency analysis is used to show the trends in respondents. Frequency analysis provides in detail information about the respondents age, gender, tenure, position and organization. This information is expressed in percentage.

Table 4.1.1: Gender

\begin{tabular}{|ll|c|c|c|c|}
\hline & \multicolumn{5}{|c|}{ GENDER } \\
\hline \multirow{3}{*}{ Valid } & Frequency & Percent & Valid Percent & Cumulative Percent \\
& MALE & 43 & 86.0 & 86.0 & 86.0 \\
& FEMALE & 7 & 14.0 & 14.0 & 100.0 \\
& Total & 50 & 100.0 & 100.0 & \\
\hline
\end{tabular}

This table shows the respondents division according to the gender. It shows that majority of respondents $(86 \%)$ are male and (14\%) respondents are females. This implies that Banking sector of Faisalabad is not biased in its employment but rather than male dominating over their female counterparts.

Table 4.1.2: Age

\begin{tabular}{|c|c|c|c|c|c|}
\hline \multicolumn{6}{|c|}{ AGE } \\
\hline & & Frequency & Percent & Valid Percent & Cumulative Percent \\
\hline \multirow{4}{*}{ Valid } & 25 TO 34 YEARS & 29 & 58.0 & 58.0 & 58.0 \\
\hline & 45 TO 54 YEARS & 2 & 4.0 & 4.0 & 62.0 \\
\hline & 35 TO 44 YEARS & 19 & 38.0 & 38.0 & 100.0 \\
\hline & Total & 50 & 100.0 & 100.0 & \\
\hline
\end{tabular}

This table shows the respondents division according to age. The table shows that $58 \%$ respondents belong to age bracket of $25-34,38 \%$ belong to the age bracket of 35-34 and 4\% respondents belong to the age bracket of 45-54. This means that the Banking sector in having young people in the service and are ready to serve for long time provided they are motivated enough to stay.

Table 4.1.3: Tenure

TENURE

\begin{tabular}{|ll|c|c|c|c|}
\hline & Frequency & Percent & Valid Percent & Cumulative Percent \\
\hline \multirow{4}{*}{ Valid } & 6 MONTHS TO 1 YEAR & 14 & 28.0 & 28.0 & 28.0 \\
& 1 TO 3 YEARS & 11 & 22.0 & 22.0 & 50.0 \\
& 3 TO 7 YEARS & 25 & 50.0 & 50.0 & 100.0 \\
Total & 50 & 100.0 & 100.0 & \\
\hline
\end{tabular}

This table shows the respondents division according to tenure. The researcher revealed that $50 \%$ of worker had experience between 3 to 7 years, $22 \%$ had 1 to 3 -year experience and only $28 \%$ had 6 months to 1 year service. This indicates that most of worker are experienced.

Table 4.1.4: Position

\begin{tabular}{|ll|c|c|c|c|}
\hline & Prequency & Percent & Valid Percent & Cumulative Percent \\
\hline \multirow{3}{*}{ Valid } & & & & \\
& & 50 & 100.0 & 100.0 & 100.0 \\
& TEMPOARARY & 50 & 100.0 & 100.0 & \\
\hline
\end{tabular}

Table show that all respondent having temporary position because all selecting bank are private. 
Table 4.1.5: Organization

\begin{tabular}{|c|c|c|c|c|c|}
\hline \multicolumn{6}{|c|}{ ORGANIZATION } \\
\hline & & Frequency & Percent & Valid Percent & Cumulative Percent \\
\hline \multirow{7}{*}{ Valid } & BANK AL-HABIB & 7 & 14.0 & 14.0 & 14.0 \\
\hline & FAYSAL BANK & 8 & 16.0 & 16.0 & 30.0 \\
\hline & MCB & 10 & 20.0 & 20.0 & 50.0 \\
\hline & MEEZAN BANK & 6 & 12.0 & 12.0 & 62.0 \\
\hline & J.S BNAK & 4 & 8.0 & 8.0 & 70.0 \\
\hline & BANK AL-FALAH & 15 & 30.0 & 30.0 & 100.0 \\
\hline & Total & 50 & 100.0 & 100.0 & \\
\hline
\end{tabular}

This table shows the respondents division according to organization.30\% people working in BANK ALFALAH, 20\% working in MCB, 16\% working in FAYSAL BANK, 14\% working in BANK AL-HABIB, $12 \%$ working in MEEZAN BANK and $8 \%$ in J.S BANK.

Frequency Analysis of Question

Table 4.1.6: Significance

\section{Stress is a Significant Issue}

\begin{tabular}{|cl|c|c|c|c|}
\hline & Frequency & Percent & Valid Percent & Cumulative Percent \\
\hline \multirow{4}{*}{ A 'Valid } & NEUTRAL & 6 & 12.0 & 12.0 & 12.0 \\
& AGREE & 28 & 56.0 & 56.0 & 68.0 \\
& STRONGLY AGREE & 16 & 32.0 & 32.0 & 100.0 \\
& Total & 50 & 100.0 & 100.0 & \\
\hline
\end{tabular}

Table 4.1 .6 shows that $88 \%$ of the employee are agree with the statement that stress is significate issue at their work place while $12 \%$ are neutral with this.

Table 4.1.7: Staff absenteeism

\section{Staff Absenteeism}

\begin{tabular}{|ll|c|c|c|c|}
\hline & Frequency & Percent & Valid Percent & Cumulative Percent \\
\hline \multirow{6}{*}{ Valid } & STRONGLY DISGREE & 1 & 2.0 & 2.0 & 2.0 \\
& DISGREE & 29 & 58.0 & 58.0 & 60.0 \\
NEUTRAL & 12 & 24.0 & 24.0 & 84.0 \\
& AGREE & 2 & 4.0 & 4.0 & 88.0 \\
& STRONGLY AGREE & 6 & 12.0 & 12.0 & 100.0 \\
Total & 50 & 100.0 & 100.0 & \\
\hline
\end{tabular}

Table 4.1 .7 shows that $60 \%$ of workers are disagree with the statement that stress causes absenteeism at their work place while $24 \%$ are neutral and $16 \%$ agree that stress causes is absenteeism hence it is clear that stress is not a cause of absenteeism at work place.

\section{Table 4.1.8: Performance}

\begin{tabular}{|c|c|c|c|c|c|}
\hline \multicolumn{6}{|c|}{ Performance } \\
\hline & & Frequency & Percent & Valid Percent & Cumulative Percent \\
\hline \multirow{5}{*}{ Valid } & DISGREE & 22 & 44.0 & 44.0 & 44.0 \\
\hline & NEUTRAL & 10 & 20.0 & 20.0 & 60.0 \\
\hline & AGREE & 11 & 22.0 & 22.0 & 82.0 \\
\hline & STRONGLY AGREE & 7 & 14.0 & 14.0 & 100.0 \\
\hline & Total & 50 & 100.0 & 100.0 & \\
\hline
\end{tabular}

The above table 4.1 .8 shows that $44 \%$ of people disagree with statement that their performance is effected by stress while $20 \%$ are neutral with this statement while $34 \%$ are agree that stress effect their performance. 
Table 4.1.9: Demands

\begin{tabular}{|ll|c|c|c|c|}
\hline & Demands \\
\hline \multirow{2}{*}{ Valid } & Frequency & Percent & Valid Percent & Cumulative Percent \\
& DISGREE & 30 & 60.0 & 60.0 & 60.0 \\
& AEUTRAL & 10 & 20.0 & 20.0 & 80.0 \\
& STREE & 5 & 10.0 & 10.0 & 90.0 \\
& Total & 5 & 10.0 & 10.0 & 100.0 \\
\hline
\end{tabular}

The above table shows that $60 \%$ of people are disagree with this statement that they did find it difficult to manage deferent demand of people while $20 \%$ agree with statement and $10 \%$ are agree that it's difficult for them to manage deferent demands.

Table 4.1.10: Job Interferes and Control Over

Job Interferes and Control Over

\begin{tabular}{|ll|c|c|c|c|}
\hline & Frequency & Percent & Valid Percent & Cumulative Percent \\
\hline \multirow{6}{*}{ Valid } & DISGREE & 4 & 8.0 & 8.0 & 8.0 \\
& NEUTRAL & 23 & 46.0 & 46.0 & 54.0 \\
& AGREE & 14 & 28.0 & 28.0 & 82.0 \\
& STRONGLY AGREE & 9 & 18.0 & 18.0 & 100.0 \\
& Total & 50 & 100.0 & 100.0 & \\
\hline
\end{tabular}

Above table show that $46 \%$ people are agree with this statement that their job interferes with their family, social reasonability's, personal need and have little control over their life at work. While $46 \%$ are neutral with this statement and $8 \%$ disagree with.

Table 4.1.11: Deadline

\begin{tabular}{|ll|c|c|c|c|}
\hline & Deadline \\
\hline \multirow{6}{*}{ Valid } & Frequency & Percent & Valid Percent & Cumulative Percent \\
& STRONGLY DISGREE & 10 & 20.0 & 20.0 & 20.0 \\
DISGREE & 33 & 66.0 & 66.0 & 86.0 \\
& NEUTRAL & 5 & 10.0 & 10.0 & 96.0 \\
& AGREE & 1 & 2.0 & 2.0 & 98.0 \\
& STRONGLY AGREE & 1 & 2.0 & 2.0 & 100.0 \\
Total & 50 & 100.0 & 100.0 & \\
\hline
\end{tabular}

Above table show that $86 \%$ people are disagree that they have unachievable dedline. $10 \%$ are neutral and $4 \%$ agree with statement.

\section{Table 4.1.12: Condition as Banker}

\section{Condition as Banker}

\begin{tabular}{|ll|c|c|c|c|}
\hline & Frequency & Percent & Valid Percent & Cumulative Percent \\
\hline \multirow{3}{*}{ Valid } & AGREE & 30 & 60.0 & 60.0 & 60.0 \\
& STRONGLY AGREE & 20 & 40.0 & 40.0 & 100.0 \\
& Total & 50 & 100.0 & 100.0 & \\
\hline
\end{tabular}

Above table shows that all people are agree with this statement.

Table 4.1.13: Satisfied

\begin{tabular}{|ll|c|c|c|c|}
\hline & Satisfied \\
\hline \multirow{2}{*}{ Valid } & Frequency & Percent & Valid Percent & Cumulative Percent \\
& STRONGLY DISGREE & 17 & 34.0 & 34.0 & 34.0 \\
& DISGREE & 30 & 60.0 & 60.0 & 94.0 \\
& AGREE & 2 & 4.0 & 4.0 & 98.0 \\
& STRONGLY AGREE & 1 & 2.0 & 2.0 & 100.0 \\
Total & 50 & 100.0 & 100.0 & \\
\hline
\end{tabular}

Above table show that $94 \%$ of the worker are disagree with that they are not satisfied with their job while only $6 \%$ are dissatisfied with their job. 
Table 4.1.14: Environment

\begin{tabular}{|ll|c|c|c|c|}
\hline & Environment & \\
\hline \multirow{6}{*}{ Valid } & Frequency & Percent & Valid Percent & Cumulative Percent \\
& STRONGLY DIAGREE & 10 & 20.0 & 20.0 & 20.0 \\
& DIAGREE & 22 & 44.0 & 44.0 & 64.0 \\
& NEUTRAL & 5 & 10.0 & 10.0 & 74.0 \\
& AGREE & 13 & 26.0 & 26.0 & 100.0 \\
Total & 50 & 100.0 & 100.0 & \\
\hline
\end{tabular}

Table above show that $64 \%$ of the worker are disagree with that the environment or their work place is not pleasant while $10 \%$ are neutral and $26 \%$ are agree that their work environment is not pleasant.

Table 4.1.15: Duties and Responsibilities

\begin{tabular}{|ll|c|c|c|c|}
\hline & Duties and Responsibilities \\
\hline \multirow{6}{*}{ Valid } & Frequency & Percent & Valid Percent & Cumulative Percent \\
& STRONGLY DISGREE & 7 & 14 & 14 & 14 \\
& NEUTRAL & 5 & 10 & 10 & 24 \\
& AGREE & 2 & 4 & 4 & 28 \\
& STRONGLY AGREE & 28 & 56 & 56 & 84 \\
Total & 8 & 16 & 16 & 100.0 \\
\hline
\end{tabular}

The above table show that $72 \%$ of the worker are clear with their duties and responsibilities while $4 \%$ are neutral and $24 \%$ said that they are not clear with their duties and responsibilities.

Table 4.1.16: Upland Change

Upland Change

\begin{tabular}{|ll|c|c|c|c|}
\hline & Frequency & Percent & Valid Percent & Cumulative Percent \\
\hline \multirow{2}{*}{ Valid } & STRONGLY DISGREE & 1 & 2.0 & 2.0 & 2.0 \\
& DISGREE & 10 & 20.0 & 20.0 & 22.0 \\
NEUTRAL & 33 & 66.0 & 66.0 & 88.0 \\
& AGREE & 3 & 6.0 & 6.0 & 94.0 \\
& STRONGLY AGREE & 3 & 6.0 & 6.0 & 100.0 \\
Total & 50 & 100.0 & 100.0 & \\
\hline
\end{tabular}

The table above shows that $66 \%$ of the people are neutral with having unplanned changes at their work place.

Table 4.1.17: Receive Enough Information

Receive Enough Information

\begin{tabular}{|ll|c|c|c|c|}
\hline & Frequency & Percent & Valid Percent & Cumulative Percent \\
\hline \multirow{6}{*}{ Valid } & STRONGLY DISGREE & 1 & 2.0 & 2.0 & 2.0 \\
& DISGREE & 2 & 4.0 & 4.0 & 6.0 \\
& NEUTRAL & 2 & 4.0 & 4.0 & 10.0 \\
& AGREE & 26 & 52.0 & 52.0 & 62.0 \\
& STRONGLY AGREE & 19 & 38.0 & 38.0 & 100.0 \\
Total & 50 & 100.0 & 100.0 & \\
\hline
\end{tabular}

This table shows that $90 \%$ people said that that have clear information about their work to carry out their activity while $4 \%$ are neutral and $6 \%$ don't have clear info about their work.

\section{Table 4.1.18: Work Related Problems}

My Colleagues are Willing to Listen

\begin{tabular}{|ll|c|c|c|c|}
\hline & Frequency & Percent & Valid Percent & Cumulative Percent \\
\hline \multirow{6}{*}{ Valid } & STRONGLY DISGREE & 2 & 4.0 & 4.0 & 4.0 \\
& DISGREE & 8 & 16.0 & 16.0 & 20.0 \\
& NEUTRAL & 32 & 64.0 & 64.0 & 84.0 \\
& AGREE & 8 & 16.0 & 16.0 & 100.0 \\
Total & 50 & 100.0 & 100.0 & \\
\hline
\end{tabular}


Above table shows that $64 \%$ are neutral with the statement that their colleagues are willing to listen their work-related problems. While $20 \%$ are disagree with that and $16 \%$ are agree with the statement.

Table 4.1.19: Administrative Support

My Administrative Head is Supportive

\begin{tabular}{|ll|c|c|c|c|}
\hline & Frequency & Percent & Valid Percent & Cumulative Percent \\
\hline \multirow{2}{*}{ Valid } & STRONGLY DISGREE & 1 & 2.0 & 2.0 & 2.0 \\
& DISGREE & 5 & 10.0 & 10.0 & 12.0 \\
& NEUTRAL & 10 & 20.0 & 20.0 & 32.0 \\
& AGREE & 17 & 34.0 & 34.0 & 66.0 \\
& STRONGLY AGREE & 17 & 34.0 & 34.0 & 100.0 \\
& Total & 50 & 100.0 & 100.0 & \\
\hline
\end{tabular}

The above table shows that $68 \%$ workers are agree that their heads support them when they have role conflict while $20 \%$ are neutral with this and $12 \%$ said that their heads don't support them.

Table 4.1.20 Participation

Participate in Banking Activities

\begin{tabular}{|ll|c|c|c|c|}
\hline & Frequency & Percent & Valid Percent & Cumulative Percent \\
\hline \multirow{4}{*}{ Valid } & NEUTRAL & 24 & 48.0 & 48.0 & 48.0 \\
& AGREE & 21 & 42.0 & 42.0 & 90.0 \\
& STRONGLY AGREE & 5 & 10.0 & 10.0 & 100.0 \\
& Total & 50 & 100.0 & 100.0 & \\
\hline
\end{tabular}

Table 4.20 reflect that $52 \%$ of the respondent said that they feel stress if they work outside of the working hours $48 \%$ are neutral with this statement.

\section{2: Reliability Analysis}

Reliability Statistics

\begin{tabular}{|c|c|}
\hline Cronbach's Alpha & N of Items \\
\hline .744 & 20 \\
\hline
\end{tabular}

Reliability analysis shows the consistency among the number of items constructed to collect the actual results. The total number of items is 20 . The overall Cronbach alpha is .744, which indicates the job stress and employee's productivity no. of items are highly consistent with each other.

\section{3: Regression Analysis}

Table 4.3.1: Model Summary

\begin{tabular}{|c|c|c|c|c|}
\hline Model & $\mathrm{R}$ & R Square & Adjusted R Square & Std. Error of the Estimate \\
\hline 1 & $-.581^{\mathrm{a}}$ & .338 & .324 & .27043 \\
\hline
\end{tabular}

The $\mathrm{R}^{2}$ is also known as coefficient of determination. It gives us information about proportion of variation in dependent variable, explained by the independent variables jointly. The value of R2 in the analysis was (.338) which stated that all independent variables jointly explained $33.8 \%$ change in dependent variable i.e. banker productivity.

\section{4: Correlation Analysis}

Correlation is used to check the mutual relationship among variables for checking the relationship will make hypothesis.

Table4.3.5: Correlation Analysis

\begin{tabular}{|ll|c|c|}
\hline & WORK STRESS & EMPLOYEES PERFORMANCE \\
\hline \multirow{2}{*}{ ST } & Pearson Correlation & 1 & $-.581^{* *}$ \\
& Sig. (2-tailed) & & .000 \\
& $\mathrm{~N}$ & 50 & 50 \\
& Pearson Correlation & $-.581^{* *}$ & 1 \\
PF & Sig. (2-tailed) & .000 & 50 \\
& $\mathrm{~N}$ & 50 & 50 \\
\hline
\end{tabular}

**. Correlation is significant at the 0.01 level (2-tailed).

The correlation table clearly shows that significant relationship exists between job stress and employee performance. These results are unexpected and completely negate the hypothesis that job stress is negatively 
related to job performance. In fact, there are higher levels of stress in the banking sector, however, due to better conditions in certain areas, for instance, control over work and support at work, the employees can perform well and stress is unable to retard the performance of the employees.

\section{CONCLUSION AND RECOMMENDATIONS}

\subsection{Findings}

- There is evidence to the effect that most employees reported to work under pressure and that they feel uncared for by the organization. Thus, the stress is a factor that the employees at banking sector of Faisalabad endure.

- $\quad$ There must be a misfit between the employees and their working environment as there is a minority of the employee who indicated that are not all happy with their working environment.

- Most of the employees reported not to participate in decision making and that could be one of the factor leading to stress.

- Most of the employees have seldom or not control over their job. When employees feel they did not have control over their jobs they may be stressed. As most of the employees have tertiary qualification and are highly competitive it can be concluded that their specialized knowledge is stifled by the lack of control over their jobs and the frustration they endure may lead to distress.

- Most of the employees who were young and highly competitive were in danger of burning out because of the work-related frustrations they experienced.

- Most of employees had thought of leaving their bank which could affect their commitment to performance.

\subsection{Conclusion}

Based on empirical findings, it is concluded that work stress is a real challenge for employees' who are working in the banking sector. It is very important that working environment is being continuously monitored for stress related factors. Further, it is not only important to monitor the factors, but to create a healthy environment in which employees' work in efficient way. For this purpose, the study is conducted to monitor the effects of job stress on employees' performance in banking sector. The variables are drawn through the banker which causes the job stress and affects the employees' performance. The variables of causing stress at job were work load, role ambiguity, and role conflict. The results indicated that stress related factors have negative effect on job environment and decreased the employees' performance. However, the management can take steps to minimize it. Organizations can reduce the level of stress on employees by redesigning jobs to lower the workload on employees cut back role conflict, and role ambiguity. Besides this organizations should also provide counseling for employees to learn stress management techniques to overcome stress problem.

\subsection{Recommendation}

Based on the findings of the research, it is recommended that the following measures be put in place to help employees of banks of Faisalabad manage and reduce stress on their work:

- The supervisors and managers need to explore the causes of the dissatisfaction of employees within the working environment. they must assess the level of their subordinate knowledge and skills, whether they will be able to meet their deadline. They must agree on performance contract so that they can give employees with job maturity and control over their job.

- Managers should invite employees, who think that they are being given jobs that are in contradiction with $\mathrm{n}$ each other, and clarify their roles. They should facilitate an employee skill audit that will help to place employees that feel underutilized.

- Management should introduce stress management technique at their banks. An Employee Assistance Program must be introducing for early identification and intervention on problems so that productivity level increases.

\subsection{Scope for Further Studies}

Area of present study can be increased from district level to state level, national level, as well as international level; Sample size can be increased; explore some other factor that contribute to occupational sector and find out the ways to resolve the lecturer's stress effectively. Other demographic details can be added in the future research and various other statistical tests can be used for comprehensive analysis \& findings.

\section{REFERENCES}

1. Blumenthal, T. (2003), Services SETA. Employee Assistance Conference Programme 2 (2). pp5 - 21

2. Bowin, R.B. \& Harvey D. (2001). Human Resource Management an Experiential Approach. 2nd Ed. New 
Jersey: Prentice Hall.

3. Bytyqi, F., Reshani, V., \&Hasani, V. (2010). Work stress, job satisfaction and organizational commitment among public employees before privatization. European Journal of Social Sciences, 18(1), 156-162

4. Chase, R. B., \& Aquilano, N. I. (1995). Production and Operations Management: Manufacturing and Service. USA, Van and Hoffmann Press.

5. Coetzee, M. \&Devillier, M. 2010. Sources of job stress, work engagement and career orientations of employees in a South African financial institution. South African Business Review. 14(1): 27-57.

6. Dua, J. K. (1994). Job stressors and their effects on physical health, emotional health and job satisfaction in a University. Journal of Educational Administration. 32, pp. 58-78.

7. Gillespie, N. A., Walsh, M.,Winfield, A. H., Dua, J., \& Stough, C. (2001) Occupational stress in universities: staff perceptions of the causes, consequences and moderators of stress. Work \& Stress. 15. pp. 53-72.

8. Haider, Y. \&Supriya, M. V. 2007. Career management: A view through stress window. International Review of Business Research Papers., 3(5): 182-192

9. Ismail, M. I. \& Hong, T. T. 2011. Identifying work related stress among empl.

10. Islam, J.N.; Mohajan, H.K. and Datta, R. (2012), Stress Management Policy Analysis: A Preventative Approach, International Journal of Economics and Research, 3(4):

11. oyees in the Malaysian financial sector. Western Journal of Management. 3(2): 229243.

12. Jamshed K. Khattak, Muhammad A. Khan, Ayaz U1 Haq, Muhammad Arif \& Amjad A.

13. Lambert, E. G. et al. 2007. The job is killing me: The impact of job characteristics on correctional staff job stress. Journal of Applied Psychology. 3(2): 117-142.

14. Luthans, F. (2002). Organisational Behaviour. New York: McGraw-Hill Companies, Inc. 